\title{
AN EXPERT TOOL FOR INTEGRATING SAFETY INTO PROJECT MANAGEMENT
}

\author{
KATRIEN B.D. BOS ${ }^{1} \&$ GENSERIK L.L. RENIERS ${ }^{1,2}$ \\ ${ }^{1}$ Centre for Economics and Corporate Sustainability (CEDON), \\ HUBrussel, Catholic University of Leuven, Belgium. \\ ${ }^{2}$ Antwerp Research Group on Safety and Security (ARGoSS), \\ University of Antwerp, Belgium.
}

\begin{abstract}
Change proposals, the introduction of new products, or changes to existing products often require new technologies and equipment to be applied to current projects in an organization or require adjustment to existing technology or equipment. Such project-based changes have an impact on safety, both direct and indirect; however, safety is often not accounted for in each phase of the project nor during the postproject period. To address this issue, this paper presents a general process scheme to be used by project management for integrating safety into each of the different project phases. Elaborating on the general process scheme, the four-leaf clover expert tool for integrating safety into a project, called 4CS $\pi$, was developed. $4 \mathrm{CS} \pi$ is a tool to be used as an aid to master the changes and to incorporate and minimize the impacts on safety during a project, as well as after project finalization.
\end{abstract}

Keywords: change management, expert tool, project management, safety management.

\section{INTRODUCTION}

Change management encompasses a number of different subjects [1], such as organizational change and cultural change. Some authors, like Burnes [2], have an integrative perspective and consider organizational and cultural changes to be closely linked, forming the ground for successful changes. Hughes discusses management techniques (such as SWOT analysis, business process re-engineering, activity-based management, quality management, and project management) to realize changes in a business environment, while stressing the importance of the practical use of any technique to incorporate successful changes. Tuning a technique into a situation (and not the opposite) can be regarded as a fundamental requirement to adequate decision-making during a change process. Iles and Sutherland [3] indicate that no existing method, strategy, or technique is applicable to all possible problems or situations. Managers need to analyze the existing situation to determine the most suitable technique. Every project is unique, so the accompanying change inducements must differ; therefore, a technique or tool integrating safety into project management needs to be flexible and dynamic to properly address the specific project.

Kleijn and Rorink [4] describe change management as the effective and process-wise steering of activities aimed at adapting an organization to certain strategic changes. Change management addresses internal changes caused by external developments and is aimed at improving effectiveness and/or efficiency. The authors suggest an integrated change management model that places both an organization's internal (strengths and weaknesses) and external (opportunities and threats) analyses in a central position. An internal analysis results in determining the currently existing situation, whereas the desired situation is established by confronting the results of the internal and external analysis. Based on the desired situation, a strategy of improvement is drafted and a change approach and plan are suggested. The principles of project management and the Plan-Do-Check-Act (PDCA) cycle can be employed to achieve continuous improvement in a complex surrounding of change management. 
Lewin discerns two necessary conditions for successful changes [2]:

i. The know-how to analyze and understand how social groups are formed, motivated, and retained. To this end, 'field theory' and 'group dynamics' were developed.

ii. The know-how to change the behavior of social groups. To this end, 'action research' and the 'three-step model of change' were elaborated.

The so-called planned change can be explained as a phased or systematic approach of one or more change processes whereby the change thresholds experienced by those involved in the change process(es) are decreased [4]. Each of the four models (field theory, group dynamics, action research, and the three-step model of change) can be regarded as belonging to the 'planned change' concept at different levels (individual, group, organizational, and even societal). To better understand planned change, the four Lewin models are briefly clarified below.

Field theory is an approach to understand group behavior by mapping the totality and complexity of the 'field' wherein the behavior takes place. According to Burnes [2], Lewin's basic premise is that current behavior (the status quo) is maintained by certain conditions or forces and that, changes in behavior result from force changes within the field. One, therefore, must identify the field forces in order to know which force influences or provokes change.

Group dynamics studies the forces that play a role in a group of people. Lewin stresses the importance of how 'the group' (viewed as a whole) shapes the behavior of the individual members [2]. Hence, to induce a change, 'group behavior' should be focused; however, understanding group dynamics does not suffice to actually implement successful changes. An additional process wherein the members can dedicate themselves toward changing their behavior is required. To this end, Lewin developed 'action research' and the three-step model.

Action research can be summarized as follows: Change demands action. Successful action results from correctly analyzing a situation by identifying all possible alternative solutions and selecting the most suitable solution. To achieve a successful change, the need to change should also be present within the individual. Action research is, therefore, an iterative process where research leads to actions, and actions lead to evaluation and further research. It is, thus, a combination of planning, taking actions, and assembling facts concerning the results of the action. To further optimize the model and to guarantee that changes are anchored into the group behavior, Lewin shaped the Three-Step Model.

According to the Three-step Model, a successful change project consists of three steps:

i. Unfreezing. Based on the field theory, the balance (status quo) has to be destabilized in order to 'unlearn' old behavior and learn new (desired) behavior.

ii. Moving. Start from the assumption (as in action research) that all possible options should be evaluated and that the most optimal choice is made based on trial-and-error.

iii. Refreezing. Re-stabilization of the group at a new balance wherein the new behavior is protected from regression.

This Three-Step Model also served as the foundation of the model of transitional change, which was briefly discussed earlier [3].

The principles of Lewin's four models can be viewed from a perspective of 'projectinduced changes' within an organization. On the one hand, safety, as an important selection criterion necessary for optimal decisions, is not used during the investigation of all possible options for a specific project. On the other hand, both the 'Check' and 'Act' phases of the 
Deming Cycle are missing in project management, hampering the effectiveness of the refreezing phase.

\section{METHODOLOGY}

The process of the project and its stakeholders are investigated and described. To this end, both an extensive literature study and in-depth interviews with project engineers, production engineers, technical staff, and others, are carried out.

The course of a project is described schematically using the different process stages and the stakeholders and the tasks involved in these stages. Interview questions are focused on the subsequent actions to be carried out within each stage, as well as on the existing procedures that are followed at the initiation of a new project. To be able to have a thorough understanding of the project and its specificities, a fixed questionnaire is not used. The main sources of information used as a starting point for the interviews are academic and professional literature, experiences with former projects, and information from existing company procedures. An insight into the different project stakeholders and their tasks is indispensable in order to be able to examine, in every phase of a project, whether (and, if so, in what way) these stakeholders should be involved when additional steps within the frame of safety have to be taken.

Subsequently, for every stage of the project process, important safety aspects are identified. The different stages are screened, focusing on the following questions: (i) what are the most important safety domains which have to be accounted for in a project; (ii) will new risks be introduced by the stage/project or will existing risks be increased; (iii) what safety compliance is required (based on safety regulations and procedures); (iv) do additional stages need to be taken; and (v) are restrictions and/or adjustments in the stage/process needed for safety reasons?

Such a project safety assessment is based on the expert opinions of prevention advisors and project stakeholders.

A tool allowing its user to account for the impact of suggested changes (resulting from a stage/project) on safety in a systematic, analytical way, while enabling its user to decrease the possible consequences of project-induced changes on safety is then developed.

\section{PROJECT MANAGEMENT AND SAFETY: CURRENT SITUATION}

\subsection{Project management of change}

We assume that the introduction of a new product or the alteration of an existing product within an organization launches the start-up of a company project. The procedure that project management utilizes to establish a new project is composed of different project phases: (i) concept, (ii) preparation, (iii) implementation, and (iv) transfer. The link between these different project phases and the well-known PDCA steps of the Deming Cycle are explained hereunder:

\section{i. Pre-project phase or concept phase-PLAN}

The main activities of the project stakeholders are drafted.

ii. Preparation phase-DO

The way in which the project stakeholders execute the activities in different project stages, is described. 


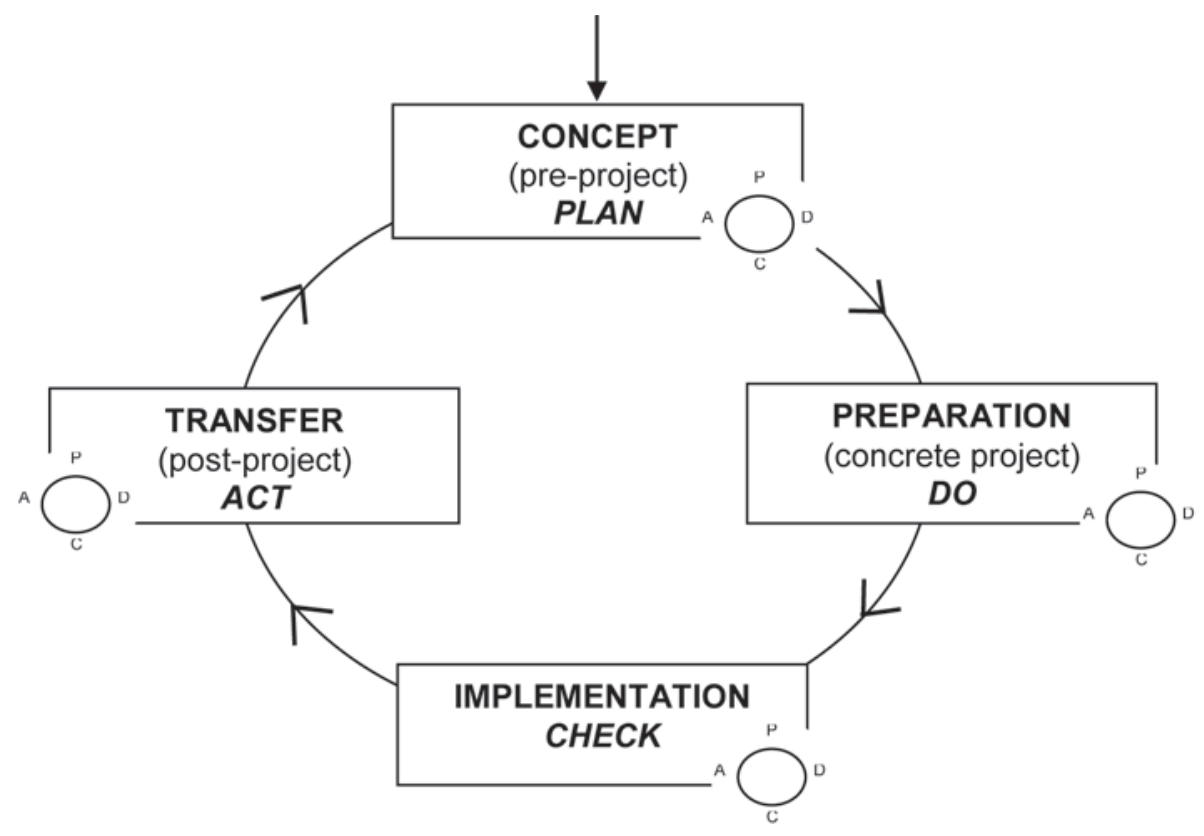

Figure 1: Global project phases and their relationship with the PDCA cycle.

\section{iii. Implementation phase-CHECK}

The project leader monitors whether the activities are properly carried out (according to agreements made in the previous phases) by the project stakeholders.

iv. Post-project phase or transfer phase-ACT

The project leader ensures that the project results are translated into the standard work of the company.

To guarantee that the four project phases are carried out adequately, it is indispensable to apply the PDCA cycle within each of them. Figure 1 illustrates the project phases described above and their link with the Deming Cycle.

The different project phases allow the systematic listing of the possible impacts of project-induced changes on safety (during the course of a project). This information can then be used to follow-up on safety during a project. An expert tool can be designed and elaborated to integrate safety into project management according to the project phases. The tool should be applicable to any company and independent of the type of project being carried out.

3.2 The project process stages in relation to a company's health safety and environment department: current practice

Based on the different project phases and the project stakeholders, current involvements of the prevention department and of safety experts are identified (for each phase).

In the concept phase, safety is (in current industrial practice) mostly not integrated into the project proposal. Sometimes, safety is integrated in the project proposal, in which usually only a screening/risk analysis needs to be carried out. 
During the preparation phase, safety is part of the competitive bid procedure to identify a supplier or contractor to perform project activities. The prevention department is not involved in a standard way in the bid procedure or the selection procedure of a supplier or contractor.

In the implementation phase, the order form or contract is drawn up and the order is placed. The order forms are signed by the prevention department, though they are not involved in drafting the contract. A risk analysis for project activities is usually carried out on demand of the project leader, whereby the supplier or contractor is also involved. If the prevention department would be notified, which is not always the case, safety experts eventually provide additional advice. During the project activities, the project leader follows-up with the supplier or contractor.

In the transfer phase, the project delivery report states that safety requirements are met and all project activities have been executed. For every project, the delivery report is signed by the company's Health, Safety, and the Environment (HSE) department (among others). The project team also provides a performance (safety) evaluation of the supplier or contractor.

\subsection{Weak points of current practices and recommendations for improvement}

It is obvious from the previous section that safety aspects are amply integrated into the different phases of the project process in current industrial project management practice. Safety is mainly checked at the completion of a project, which can lead to a sub-optimal situation where added-on safety measures are taken instead of inherent safety measures.

Safety should be integrated proactively into project management and the impact of changes on safety (due to a project) should be assessed throughout the project at the earliest possible stage. The following sections, 3.3.1 through 3.3.4, provide an overview of the weak points of current industrial practice for the four process phases.

\subsubsection{Concept phase}

Safety is not integrated into the concept phase of a project, and the company's HSE department is not involved at this stage. Some safety-related items of consideration that should be implemented at this early project stage are not taken into account, leading to a sub-optimal situation. The envisioned expert tool should, therefore, be designed to account for safety in this early project stage. This can be accomplished by drafting and employing a list of safetyrelated items of consideration on which the prevention department should give advice. These items of consideration need to be chosen based on their degree of importance regarding the following: (i) possible project-induced and safety-related changes concerning design and layout (e.g. a request for a change of design to improve ergonomic handling); (ii) possible project-induced and safety-related impact on project budget and timing (e.g. the request of permits, input of hazardous products); and (iii) possible project-induced and safety-related legal requirements, norms, and company standards.

Carrying out a risk analysis in this phase (project management together with the Safety, Health and Environment (SHE) department) using a list of items of consideration should lead to a number of requirements to be taken into account in the implementation phase.

\subsubsection{Preparation phase}

In the preparation phase, various agreements to be implemented in the next phase are settled. Thus, a request for change (e.g. preventive measures from the SHE department) in a later 
project phase results in project delays. In industrial practice, the project leader usually decides who to involve in this preparatory phase and the SHE department is often not involved at this stage of the project. The influence of the company's SHE department is therefore limited, since major changes are very difficult to suggest at a later stage.

In the competitive bid procedure, safety engagements of suppliers and/or contractors are investigated and assessed only by project management at the initiative of the project leader; however, such safety engagements should always be investigated and should be part of the competitive bid procedure of a company. Moreover, the company's SHE department should be involved in this procedure. A contractor or supplier that can show excellent internal safety performance results will most likely display a similar level of safety while working under another company or delivering products/services. Hence, the involvement of the company's SHE department concerning in the selection procedure of a contractor or supplier should be part of the bid discussion.

\subsubsection{Implementation phase}

In the implementation phase, the contractor(s) and/or supplier(s) are first selected. Second, a risk analysis has to be performed according to existing procedures and documents within the company. These documents guide how the project leader needs to follow-up the work in the implementation phase. While executing the risk analysis, the expert tool helps its user to identify and to assess both risks of the contractor(s) and/or supplier(s) as well as risks inherent to the company. It should be noted that the procedures and documents should be drafted such that internal staff may also utilize them.

Current industrial practice has some important drawbacks. Risks are usually identified once and are not reviewed during the work. Sometimes, especially in case of long-term projects, circumstances change and risks are prone to change as well. Moreover, no dynamic (time-dependent) procedure is available for shifting responsibilities and granting permission for executing process activities. Some dynamism into the project procedure is needed to account for changing situations and circumstances. To take these safety disadvantages of current project management into account, the project leader should systematically follow-up on the safety performance of the contractor(s) and/or supplier(s) during the work, and should discuss their performance with them if and when safety infractions or deviations are identified. This way, risks are controlled at all times and the involved parties are informed throughout the project.

When the installation is released for start-up, the definitive cut-over takes place. At present, no relationship exists between the requirements in the concept and preparatory phases and the achievements in the implementation phase. The expert tool needs to take this drawback into account and should establish the way to ensure such a relationship.

\subsubsection{Transfer phase}

A smooth and successful transition between the end of the project and standard production within the company requires a clear overview of the necessary actions that should be undertaken by the project leader to ensure that the involved department of the company has adequate knowledge of the project's results and their application(s). Necessary training and adjusted instructions should be provided in case of procedural changes. These instructions and training sessions should result from a task risk analysis of company personnel responsible for executing the project's results. These points will be part of the expert tool discussed in the following section. 


\section{THE FOUR-LEAF CLOVER FOR SAFETY AND PROJECT INTEGRATION EXPERT TOOL}

The Four-Leaf Clover for Safety and Project Integration (4CS $\pi$ ) expert tool was developed to account for the impact of project-induced changes on safety. The tool can be regarded as an electronic 'change roadmap', guiding a project leader in the area of safety throughout a project. The 4CS $\pi$ expert tool serves to control the impact of any project-induced changes on safety. For developing the expert tool, project information and experiences from a multinational food company were leveraged with academic and professional safety documentation and guidelines. In the following sections, the tool software and its generic applicability are thoroughly explained.

\subsection{The four-leaf clover model}

Figure 1 relates the four project phases with the PDCA cycle. This relationship forms the starting point for the tool's development. Within every project phase, another PDCA cycle is integrated. These intra-project phase PDCA cycles are further developed according to Table 1 to construct $4 \mathrm{CS} \pi$.

Since the four project phases represent consecutive steps functioning as a chain, conceptually connecting the project phases ensures smooth transitions between the completion of one phase and the start-up of another. To this end, an overlap between the Act-step (of the PDCA cycle) of one phase and the Plan-step (of the PDCA cycle) of the consecutive phase was envisioned (see Table 1). Table 1 illustrates that the project phases are not considered separately and that the expert tool provides a smooth transition between the different project phases. Figure 2 illustrates the model evolving from the four project phases to a four-leaf clover model. The model symbolizes the mutual relationship between the project phases, whereby the first phase initiates at the stalk of the clover.

Table 1: Filling in the intra-project phase PDCA cycles.

\begin{tabular}{lll}
\hline 1. Concept (Plan) & P & Collect data \\
& $\mathrm{D}$ & Research data \\
2. Preparation (Do) & $\mathrm{C}$ & Additional safety demands or measures \\
& $\mathrm{A} / \mathrm{P}$ & Technical items of consideration \\
& $\mathrm{D}$ & Competitive bid procedure \\
& $\mathrm{C}$ & Selection of supplier(s) and/or \\
& & contractor(s) \\
3. Implementation (Check) & $\mathrm{A} / \mathrm{P}$ & Risk analysis of the project activities \\
& $\mathrm{D}$ & Monitor activities, assess, and evaluate \\
4. Transfer (Act) & $\mathrm{C}$ & Cut over \\
& $\mathrm{A} / \mathrm{P}$ & Operational items of consideration \\
& $\mathrm{D}$ & Transfer responsibilities \\
& $\mathrm{C}$ & Adapt documentation \\
& $\mathrm{A}$ & Integration in standard company \\
& & processes \\
\hline
\end{tabular}



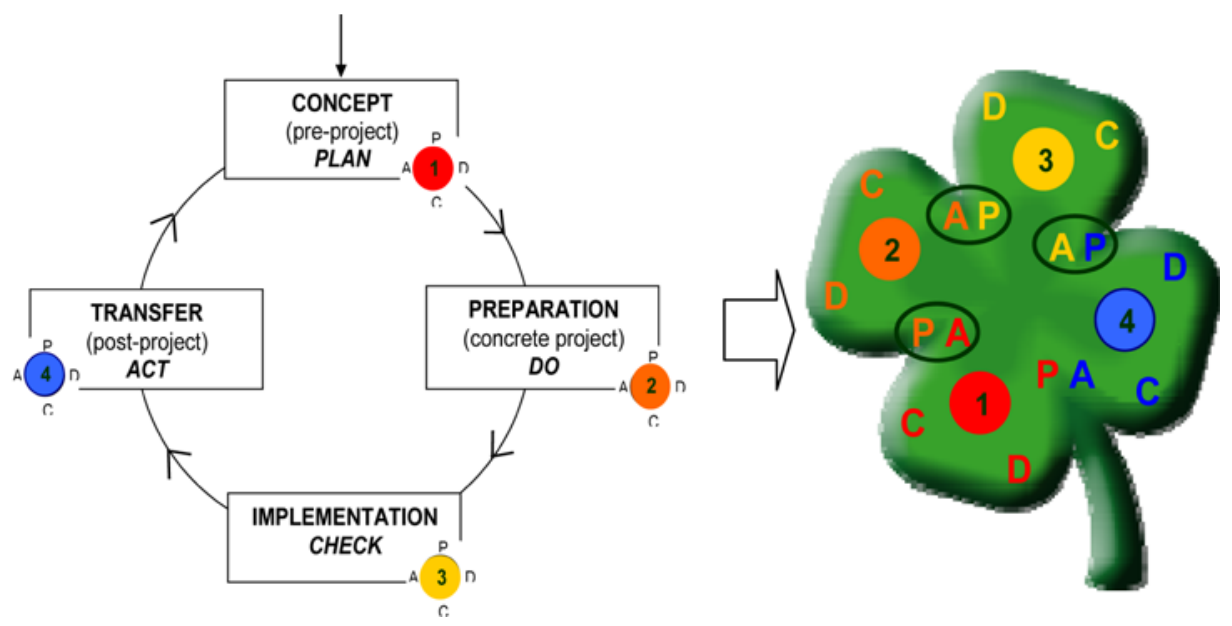

Figure 2: The four-leaf clover model.

\section{CSTr expert tool}

created by Katrien Bos

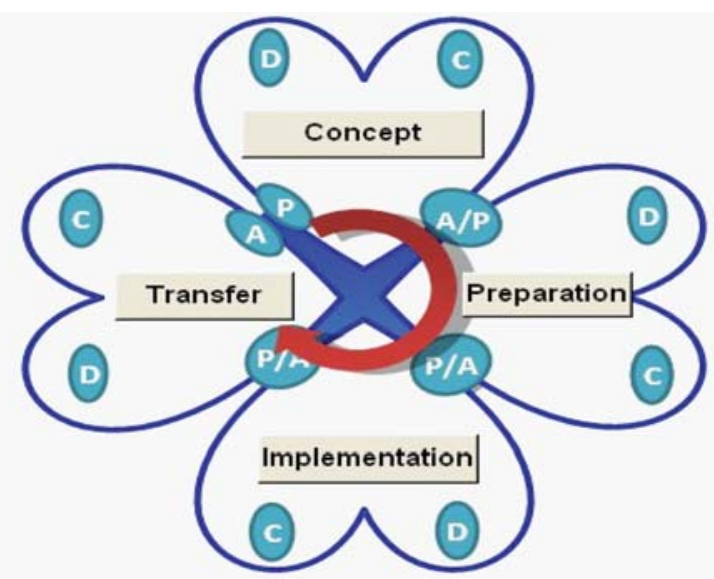

Reset

- $\backslash$ Clover overview / Concept / Preparation K Implementation / Transfer /

1<

Figure 3: Snapshot of the introductory page of $4 \mathrm{CS} \pi$.

The Four-leaf clover model is a visual aid for a project leader to identify the stage of the project while using the expert tool. Figure 3 presents a snapshot of the $4 \mathrm{CS} \pi$ expert tool software.

In the following sections, the development of the different phases in the $4 \mathrm{CS} \pi$ expert tool will be discussed. 


\subsubsection{Concept phase in $4 \mathrm{CS} \pi$}

In the concept phase, items of consideration are taken into account that address the following:

(i) the design and layout of machines, installations, equipment, and infrastructure and their impact on ergonomics; (ii) a list of risks based on safety regulations and guidelines; (iii) compliance with safety legislation; and (iv) required activities that have an impact on the project budget and timing (e.g. application for licenses, explosion safety study, etc.).

The first step in the concept phase addresses data collection (Plan).

In this step, the project leader collects some important safety-related data from the supplier(s) and/or contractor(s). This information is used to verify the impact of the projectinduced changes on equipment, machines, infrastructure, and fire safety, as well as the use, storage, and production of hazardous substances. For example, information such as material safety data sheets and process or machine design information is gathered.

The second step in the concept phase addresses an investigation into the collected data (Do).

Project-induced changes require a check regarding their compliance with existing legislation and regulations. The necessity of extra features or demands should be verified. For example, if the influence on fire safety has been established in the previous step, this step involves investigating whether action is required and, if so, which alterations are possible.

The third step in the concept phase addresses drafting additional safety demands or measures (Check).

Measures need to be taken when research in the previous step shows that certain requirements were not met. For example, project activities may only commence when the fire insurer has approved the changed sprinkler installation design, which was re-designed as a result of fire safety demands.

During the concept phase, no direct impact on safety will be noticeable. Nonetheless, a screening of project-induced changes and possible alterations and additional actions and demands is of great importance to proactively assess possible increases in project costs and time. The result of the concept phase transpires into a list of additional safety demands or measures that will be taken into account in the preparation phase in the competitive bid procedure. Figure 4 presents a snapshot of the $4 \mathrm{CS} \pi$ concept phase.

\subsubsection{Preparation phase in $4 \mathrm{CS} \pi$}

While the concept phase focused on general aspects with respect to design, compliance, budget, and timing, the preparation phase focuses on concrete technical details.

The first step from the concept phase is the same as the plan step from the preparation phase.

In this step, a list is drafted of the following technical items of consideration:

- Fire safety-emergency facilities

- Machine safety

- Ergonomics

- Inspections

For each of these four categories, a number of minimum required technical safety measures are listed.

The second step in the preparation phase addresses drafting the competitive bid procedure (Do).

In this step, two components are addressed-working with supplier(s) and/or contractor(s) and issues that have to be part of the competitive bid procedure. 


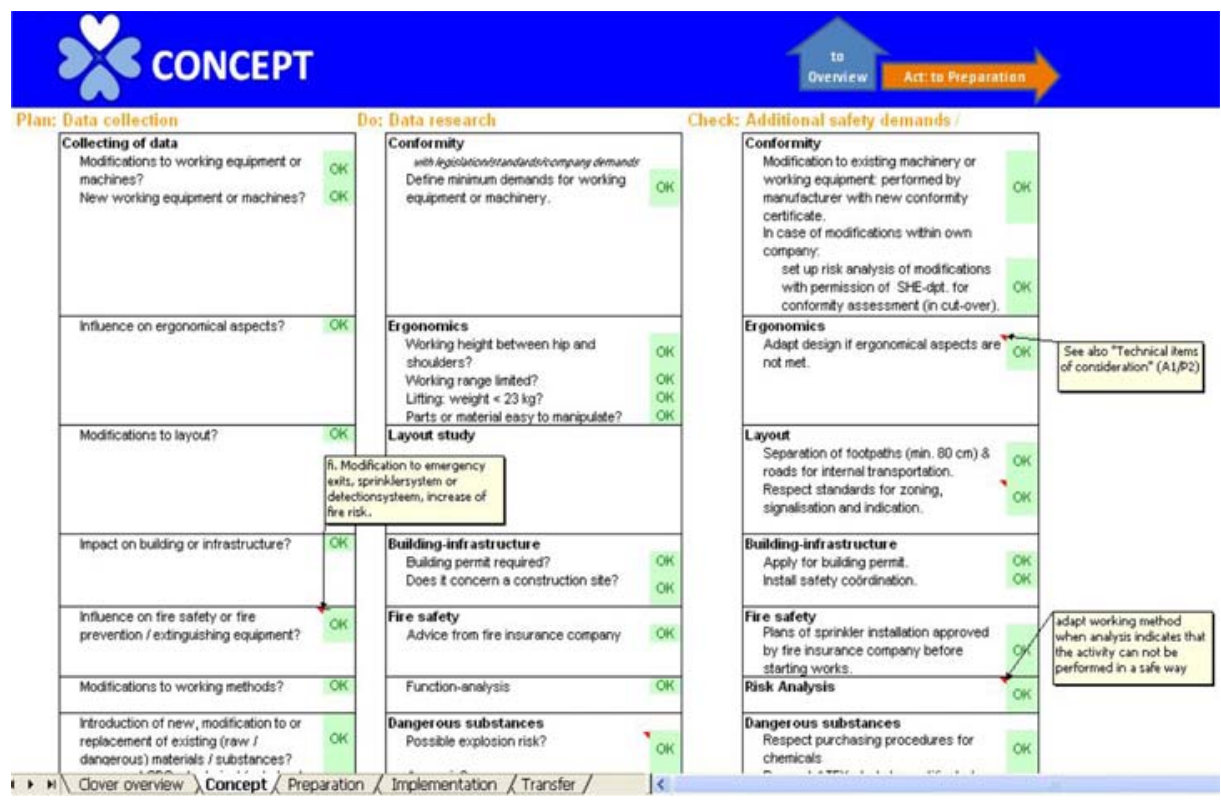

Figure 4: Snapshot of the 4CS $\pi$ concept phase.

A company procedure for working with contractor(s) and supplier(s) needs to be included/ inserted in the expert tool. The contents of the competitive bid procedure should also be addressed in the tool and documents that should be part of the bid (such as safety engagements, additional safety demands, and additional measures from the concept phase) are taken into account.

The third step in the preparation phase concerns the placing of the bid (Check).

In this step, the following items of consideration are included: discussing the bids with the company's SHE department and subsequent confirmation of the selection of supplier(s) and/ or contractor(s) and then having the company's SHE department sign the contract or order form.

Documents that must be part of the competitive bid procedure as standard procedure have been included in the expert tool. This will allow each project leader to require the use of these documents for a bid. In addition, the prevention department will be asked for advice at the bid discussion to make the contractor selection. Figure 5 presents a snapshot of the $4 \mathrm{CS} \pi$ preparation phase.

\subsubsection{Implementation phase in $4 \mathrm{CS} \pi$}

The first step from the preparation phase, which is the same as the plan step from the implementation phase, is carrying out a risk analysis of the project activities.

The expert tool offers the necessary documentation and procedures with which the risk analysis can be successfully executed. Furthermore, the identified risks of the company and the project executor are integrated and all involved employees are informed of prevention measures and responsibilities.

The second step in the implementation phase concerns monitoring and evaluating the project activities (Do). 


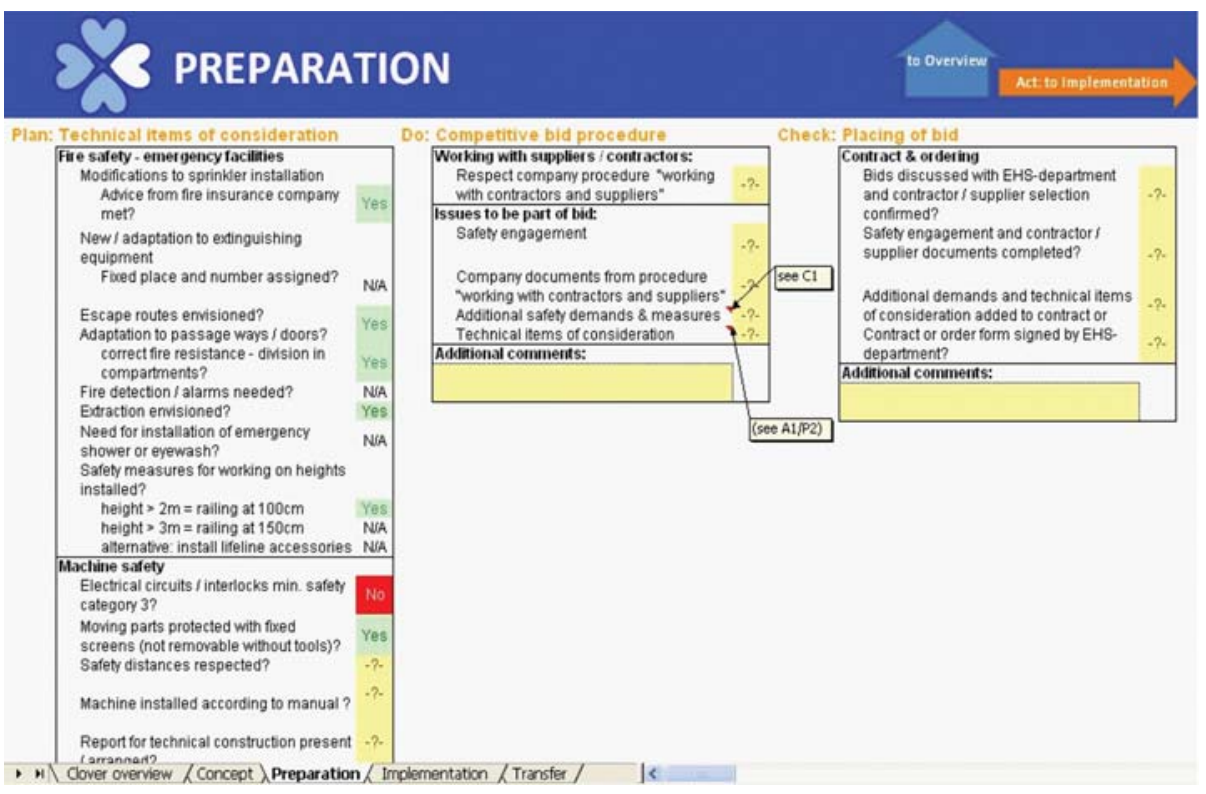

Figure 5: Snapshot of the $4 \mathrm{CS} \pi$ preparation phase.

In this step, a number of action points are defined in the expert tool to review risks at the start of project activities, as well as in case of deviation from planned activities and of nonanticipated circumstantial changes. In these cases, a feedback loop is provided to one or more previous phases in $4 \mathrm{CS} \pi$. Furthermore, a number of topics regarding required permits to work are included in the tool.

The third step in the implementation phase concerns the cut-over (Check).

A checkup of the requirements listed in the concept and preparation phases is performed in this step. The tool also notes that the project leader includes the permission of the company's SHE department for a cut-over. The presence of certificates concerning conformity and specific documents from supplier(s) and/or contractor(s), as well as signalization etc., are checked. Figure 6 presents a snapshot of the $4 \mathrm{CS} \pi$ implementation phase.

\subsubsection{Transfer phase in $4 \mathrm{CS} \pi$}

In the transfer phase, potential risks that may manifest in the project afterlife are considered and will aid in suggesting remediating actions and/or prevention measures. For a number of items of consideration, responsibilities are fixed in order to stress (and anticipate) the shared responsibilities between the project leader and the concerned departments of the company once the project has been terminated.

In the first step from the implementation phase is the same as the plan step from the transfer phase.

In this step, a number of operational items of consideration are listed, including, but not limited to, the following:

- adapting or drawing up maintenance procedures for the project's result(s);

- integrating maintenance planning of the project's result(s) into the company's maintenance procedures; 


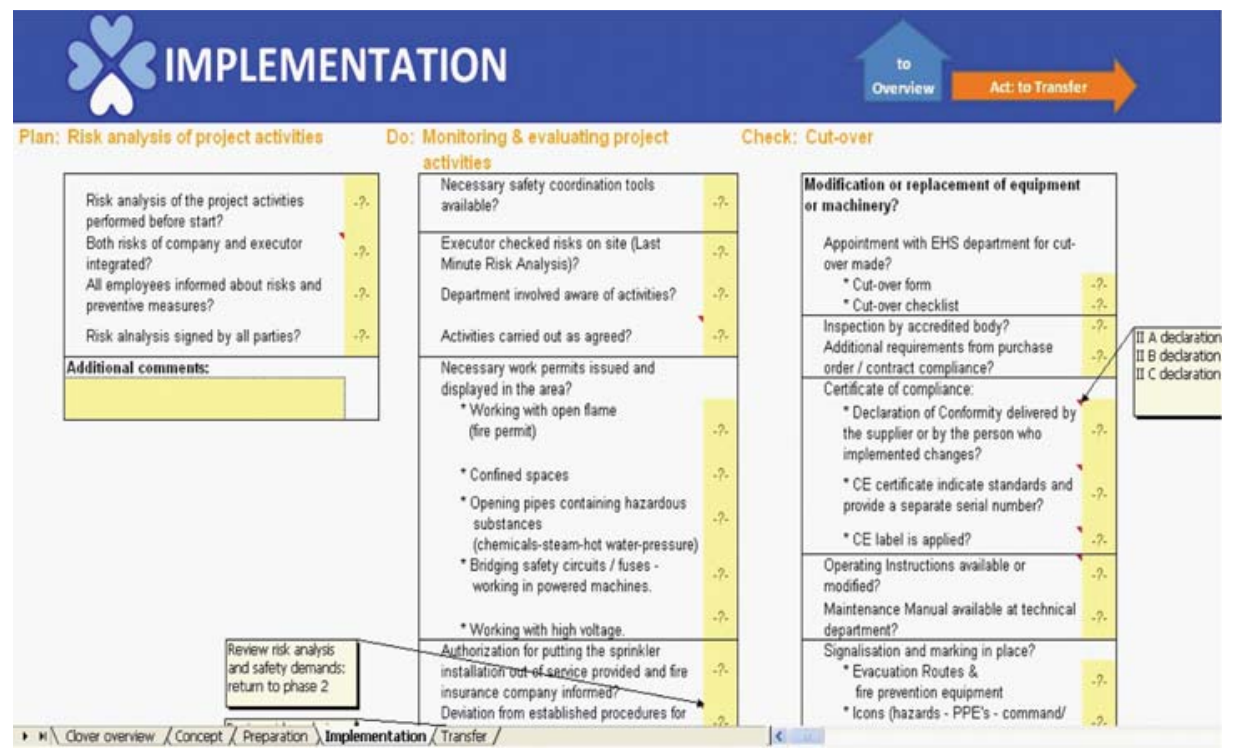

Figure 6: Snapshot of the $4 \mathrm{CS} \pi$ implementation phase.

- training;

- formulating work instructions for the project's result(s); and

- performing a task risk analysis for the project's result(s).

The second step in the transfer phase addresses the transfer of responsibilities (Do).

Activities resulting from periodic inspections are included in this step. An individual who will carry responsibility for the project's result(s) is appointed from within the company's department where the project was completed. The project leader relays the necessary information (which is pointed out by the expert tool) for adequate task performance to this individual.

The third step in the transfer phase addresses the continuous adaption of documentation (Check).

This step includes the emergency plan, safety procedures, and technical documentation. The emergency plan encompasses fire department plans, evacuation plans, and the explosion zoning plan. Safety procedures include a safety manual, working procedures, and check lists. Technical documentation includes, but is not limited to, electric and mechanical schemes and automatic systems with visualization of process schemes.

The fourth step in the transfer phase addresses the integration in standard company working processes (Act).

This step includes specific details for a smooth integration of activities required for the project's result(s) into daily company activities. The act step in the transfer phase is independent from the plan step in the concept phase since every PDCA cycle of a project process deals with a different project. Figure 7 provides a snapshot of the $4 \mathrm{CS} \pi$ transfer phase.

\subsection{Discussion of $4 \mathrm{CS} \pi$ execution}

The developed expert tool helps a project leader to take precautionary measures in a variety of areas and at different points in time during a project in order to limit the impact of projectinduced changes on safety. 


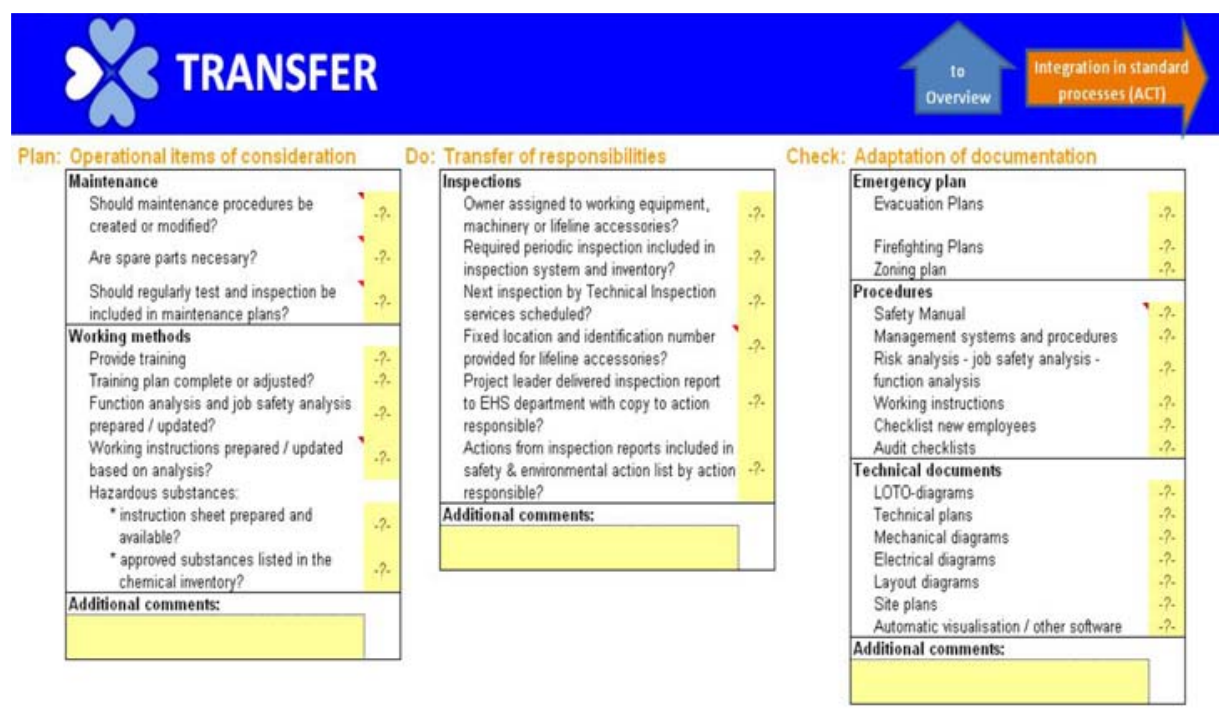

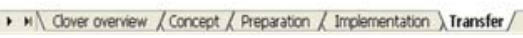

\section{k.}

Figure 7: Snapshot of the $4 \mathrm{CS} \pi$ transfer phase.

The use of lists of 'items of consideration' avoids the tool from becoming outdated when certain procedures or legal requirements change. Subsequently, $4 \mathrm{CS} \pi$ is a dynamic and flexible tool that can be adjusted when/if new procedures or new legislation comes into effect. The expert tool can also be easily expanded with additional items of consideration, without adapting current lists. As an example, depending on its user, the tool may include specific items of consideration belonging to other domains such as quality, environment, and security.

The structure for the tool was drawn up based on four (general) project phases (Figure 1) and the four-leaf clover model (Figure 2). This structure ensures that the $4 \mathrm{CS} \pi$ tool can be employed in different domains and for different types of projects. Moreover, the tool is conceptualized in a way that guarantees its independence of company culture or company needs. The utilization of the well-known PDCA cycle for the entire project, as well as within every project phase, ensures that an integrated procedure for continuous improvement can be introduced in the project. Each step within the PDCA cycle can be customized for any company.

Figure 8 shows the corresponding colors for the level of completion of the different stages of the tool. Blue indicates completion of the phase, red indicates partial completion of the phase, and white indicates that the phase has not yet begun.

The software for the tool was developed by the authors and the tool is currently being implemented in a major international food company. Implementation of the tool required several procedural and process changes within the company.

\section{CONCLUSIONS}

Controlling the consequences of project-induced changes on safety is not an easy task. The development of an expert tool that will help a project leader to make efficient decisions regarding safety in every phase of a project will be very useful. A generalized project process encompasses four project phases that can be linked to the PDCA cycle: 'Concept' or 'PLAN', 'Preparation' or 'Do', 'Implementation' or 'Check', and 'Transfer' or 'Act'. To ensure a 


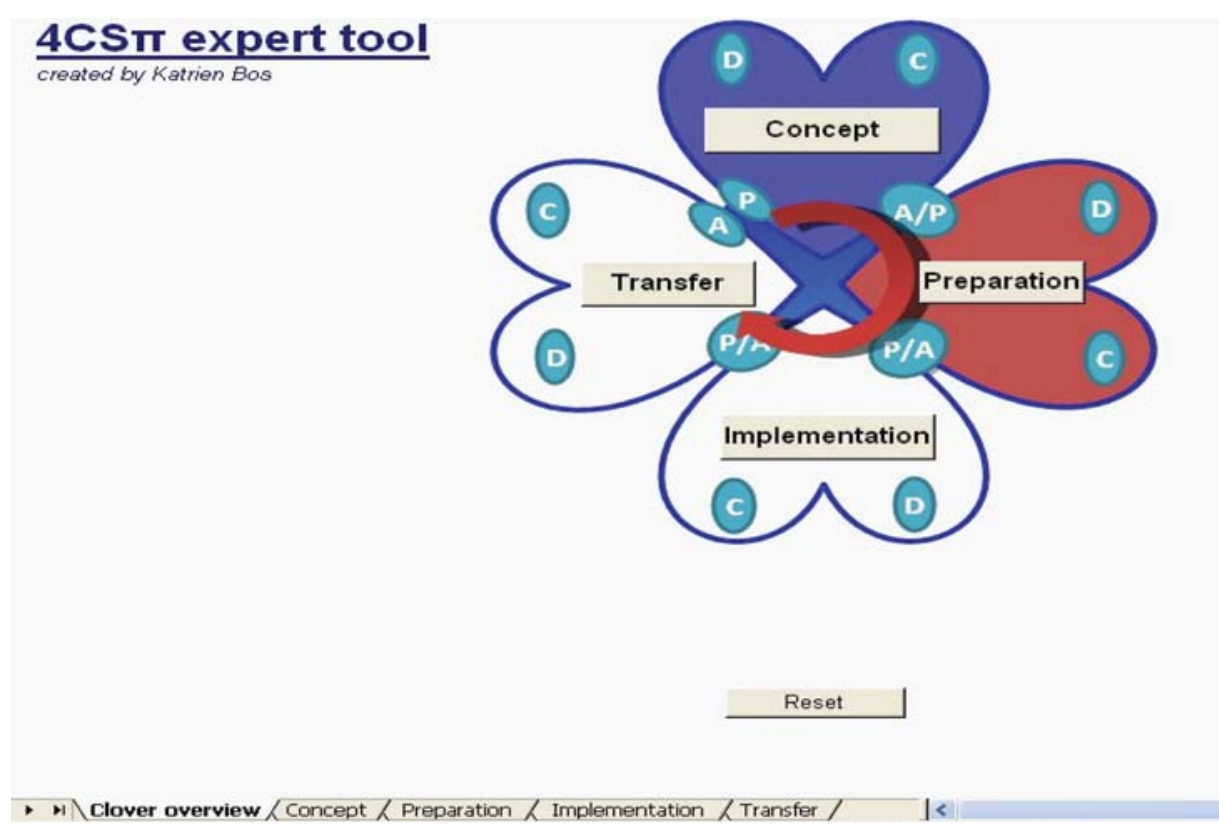

Figure 8: Corresponding colors for the level of completion of each phase of $4 \mathrm{CS} \pi$.

smooth transition between the four phases, the elaborated expert tool, $4 \mathrm{CS} \pi$, integrates within every project phase an extra PDCA-cycle, in which the act step of the previous phase equals the plan step of the consecutive phase. Every PDCA step within the four project phases was further elaborated and explained, resulting in an easy-to-use and understandable step-by-step process that may identify and control the safety impacts during any project. The expert tool provides the user with the main items of consideration (including procedures to follow and mitigation measures) throughout the execution of any project. 4CS $\pi$ introduces safety in all parts of a project and carries out risk analyses in the different phases to ensure or increase safety levels.

\section{REFERENCES}

[1] Hughes, M., The tools and techniques of change management. Journal of Change Management, 7(1), pp. 37-49, 2007. doi: http://dx.doi.org/10.1080/14697010701309435

[2] Burnes, B., Kurt lewin and the planned approach to change: a re-appraisal. Journal of Management Studies, 41(6), pp. 977-1002, 2004. doi: http://dx.doi.org/10.1111/j. 1467-6486.2004.00463.x

[3] Iles, V. \& Sutherland, K., Organisational Change: A Review for Health Care Managers, Professionals and Researchers, London School of Hygiene \& Tropical Medicine: London, 2001.

[4] Kleijn, H. \& Rorink, F., Verandermanagement: 2de editie, Pearson Education: Nederland, 2009. 